\section{EMBRYRIDDLE}

Aeronautical University

SCHOLARLY COMMONS
Journal of Aviation/Aerospace

Education \& Research

Volume 24

Number 2 JAAER Winter 2015

Article 1

Winter 2015

\title{
Real-time Computer-based Simulation as an Intervention in Aerodynamics Education
}

\author{
Kevin T. Rigby \\ Embry-Riddle Aeronautical University - Daytona Beach, rigbyf2f@erau.edu
}

Follow this and additional works at: https://commons.erau.edu/jaaer

\section{Scholarly Commons Citation}

Rigby, K. T. (2015). Real-time Computer-based Simulation as an Intervention in Aerodynamics Education. Journal of Aviation/Aerospace Education \& Research, 24(2). https://doi.org/10.15394/jaaer.2015.1634

This Article is brought to you for free and open access by the Journals at Scholarly Commons. It has been accepted for inclusion in Journal of Aviation/Aerospace Education \& Research by an authorized administrator of Scholarly Commons. For more information, please contact commons@erau.edu. 


\section{Introduction}

A focus of many aeronautical science departments is the education and training for professional pilot. Concepts taught in many courses may play an important role during a critical situation in their aviation career. The Aeronautical Science Department at Embry-Riddle Aeronautical University (ERAU), Daytona Beach Campus, blends academic study with flight training to provide a solid foundation for corporate, airline, and military aviation. Long-term retention is important so that they may recall the material and use it later in their career. However, for the retention of learned material to take place, the students must first learn the material. Performance of learning objectives is crucial to the process of learning, and, ultimately, the application of the content at a later time.

At many universities, aerodynamics courses are taught in the following manner: lecture, working examples, and the assignment of problems for students to solve. Some students struggle with the material presented in both Aerodynamics and Performance (applied aerodynamics). One instructional intervention that has been suggested as a way to increase performance and reduce attrition is simulation.

This study replicated two studies, integrating the methodology from each study. The parts of the study replicating Campbell, Bourne, Mosterman, and Brodersen's (2002) work examined the efficacy of software simulations. Using Rodgers and Withrow-Thorton's (2005) work, the effect of media on student motivation was explored.

\section{Simulation}

Computer-based simulations have become commonly available. They can be purchased commercially and run on a high-end mainframe, or downloaded for free via the Internet and run on a personal computer. "A computer-based simulation is a program that embodies some model 
or an aspect of the world, allows the user to make inputs to the model, runs the model, and displays the results" (Laurillard, 2002, p. 127). Simulations are used for various reasons in education and training to include: replacing dangerous situations that may occur such as in firefighting (Proctor \& Gubler, 2001), to teach cell theory in biology (Wekesa, Kiboss, \& Ndirangu, 2006), to teach the effects of international trade agreements in economics (Schmidt, 2003), or to replace costly and/or large equipment (Campbell et al., 2002) that may not be available to all institutions, such as a wind tunnel. Simulations provide the opportunity to assess learning in multiple ways. Smith and Ragan have stated that "[s]ince it is often impractical or undesirable to assess a student's performance in real-life circumstances, we may wish to simulate those circumstances" (Smith \& Ragan, 1999, p. 100).

The increased use of computers in the education environment has resulted in greater adoption of simulation as a teaching tool. "Simulations are recognized as an efficient and effective way of teaching and learning complex and dynamic systems for engineering education" (Davidovitch, Parush, \& Shtub, 2006, p. 289). For example, combined with problem solving and decision making requirements, simulation can offer endless opportunities for exploration in realtime.

\section{Method}

The research design used in this study was a pretest, posttest quasi-experimental method. The study was performed during two sections of AS 309 Aerodynamics at ERAU, Daytona Beach Campus. The researcher had no access to student assignments since the students selfselected which class they would attend at registration. One section served as the control group and one section received the treatment. The control group received standard lecture followed by a paper-based lab. The treatment group received the standard lecture followed by a computer- 
based simulation.

The FoilSim simulation was used during the lab session. FoilSim is free and available for download or can be run as a JavaApplet. The FoilSim program was developed by NASA Lewis Research Center as an aerodynamics teaching and learning tool. The goal of FoilSim is to teach classical airfoil theory. Benson (1996), the developer of the original VU-FOIL program which subsequently evolved into FoilSim, has written that "the interactive, graphical nature of computer output can provide the student with information in ways which are not possible with standard text-books, lectures, or other visual aids" (p. 1). FoilSim is considered a virtual simulation because it runs on a computer, allows real-time user interactivity through graphical user interface, and provides instant numeric and graphical feedback.

The experiment spanned two classes in which pretest, lecture, lab, posttest, and the Instructional Materials Motivation Survey (IMMS) were administered. An ANCOVA was used to test for a difference in the means of the two groups' posttest.

The IMMS was administered to evaluate student motivation as it related to the use of instructional media during the study. The IMMS was evaluated using the total score method in accordance with Keller's (1993) instructions for the administration of the IMMS.

\section{Participants}

The participants included students from the ERAU College of Aviation. The majority of students in the study were from the Aeronautical Science Degree program and were on a pilot track. However, there was small representation of students from Safety Science, Meteorology, and Aeronautics majors.

\section{Research Questions and Hypotheses}

The researcher investigated the following research questions and answered the following 
hypotheses in this study:

1. How does the instructional strategy of simulation influence performance in an Aeronautical Science aerodynamics class?

Hypothesis 1: Students who use the computer-based simulation will have a higher level of performance on a posttest than control group students.

2. How does the instructional strategy of simulation influence motivation in an Aeronautical Science aerodynamics class?

Hypothesis 2: Students who use the computer-based simulation will have a higher level of motivation as measured by post treatment instrument.

3. What are the relationships between performance and motivation?

Hypothesis 3: There will be relationships between performance and motivation.

\section{Variables}

The independent variable was the instructional strategy of a computer-based simulation used to teach aerodynamics concepts. The dependent variables were performance and motivation as measured by post intervention instruments.

Independent variable. In this study, student performance depended upon the instructional strategy of using a computer-based simulation to teach aerodynamics concepts. The independent variable did not change and in this study was the manipulated variable. Therefore, the independent variable was the instructional strategy of using a computer-based simulation.

Performance. Student performance was the first dependent variable. Performance for the purpose of this study was how well someone can do something (Gagné, 1977). The something in this study was to answer questions about what students learned during a lecture and follow-on lab session about lift. Student performance depended upon the independent variable 
of the use of a computer-based simulation. A pretest was administered and used as a covariate to statistically control for nonequivalence of the two groups in prior knowledge. Student performance data was measured by a posttest. Student performance was based on the post session quiz scores.

Motivation. Student motivation was the second dependent variable. Motivation in this study was considered in accordance with Keller's Attention, Relevance, Confidence, Satisfaction (ARCS ) model and was considered in terms of reactions to instructional materials (Keller, 2006). Student motivation depended upon the independent variable of the use of a computerbased simulation.

Motivation was measured using the Instructional Materials Motivation Survey (IMMS). Student motivation was based on the student's total scale score. The total scale score was based on a set of subscales that measure student motivation reactions to the ARCS model components of gaining and keeping attention, seeing relevance, gaining confidence, and gaining satisfaction by using the instructional materials (Keller, 1987).

\section{Control Group and Treatment Group}

The subject sample was comprised of students in an aviation program. Subjects were enrolled in two sections of AS 309 Aerodynamics. One section was used as a control group and the other served as the treatment group.

Control group. The control group received no experimental manipulation. The control group was taught as the course has been in the past and was used as a baseline comparing against the dependent variable of performance.

Treatment group. The treatment group was exposed to the change in the independent variable of having a computer-based simulation used in the lab session. The treatment group was 
taught using the computer-based simulation and was used to compare against the dependent variables of performance and motivation.

\section{Course Content}

The instructional material in each course was identical up to the point at which the treatment was applied, and the content was identical throughout the course per the AS 309 course syllabus. Labs in the course are typically paper-based and students use their calculators, look-up tables, and graphs to complete the labs. The treatment was the use of the computer-based simulation to complete the lab.

The courses covered the same material on the days that they met. The two classes met on Tuesday and Thursday, and started and finished on the same dates.

Pretreatment content. Content prior to the treatment intervention included a review of math and physics concepts that were used throughout the course. Other lessons included atmospheric calculations, airspeed calculations, Bernoulli's equation, airfoils, and aerodynamic forces. These lessons were prerequisite knowledge for understanding the concept of lift.

The pretest was applied at the end of this phase. An example of a pretreatment question is: If you go up in altitude, lift will: a. increase, b. decrease, c. stay the same. General questions were asked in this manner directly related to the follow-on instructional session.

Treatment content. The lesson that had the treatment applied was the critical lesson on the topic of lift. This lesson covered factors that affect lift. Lift is a force that was calculated in pounds.

The post lesson lab required students to answer questions related to changing variables in the lift equation. The control group performed the lab on paper. The treatment group performed the lab using the FoilSim program. Students received prior instruction on how to use the 
FoilSim program. The instructor was available for assistance throughout the lab.

During the lab session, students were given a question that was tested conceptually on the pretest, discussed during a lesson example, and tested conceptually on the posttest. By using this theme in the instructional design of the course, congruity persisted throughout all of the instructional materials.

Upon completion of the treatment, students were given the posttest. Following the posttest, the IMMS was administered.

An example of a posttest question is: All other variables held constant, if altitude is increased lift will: a. increase, b. decrease, c. stay the same. Once again, this method is an example of the congruity and consistency of the instructional materials.

\section{Instruments}

The instruments used in this study were a pretest, a posttest, and the IMMS. The pretest and posttest were developed by the researcher. The IMMS was developed by Keller (1993).

Pretest. The pretest consisted of questions related to aerodynamics and lift and was given as a presession quiz. The pretest evaluated equivalence of prior knowledge of the material presented in the instructional session for which the treatment was applied. This prior knowledge included questions about coefficient of lift $\left(\mathrm{C}_{\mathrm{L}}\right)$ versus angle of attack (AOA) curves, density effects on lift, and airfoil design effects on lift.

Posttest. The posttest consisted of questions related to the instructional session for which the treatment was applied. These questions were related to concepts that were presented throughout the lesson. The posttest was used to test student performance related to identifying relationships in lift. Questions posed a specific flight condition, then a change in the flight condition, and students had to determine conceptually how lift would change, or how to increase 
or decrease lift by changing the flight condition.

IMMS. The IMMS is a 36 question 5-point Likert scale response questionnaire. The questions relate to the four elements of the ARCS model: Attention, Relevance, Confidence, and Satisfaction. The IMMS has been used in many studies over the years in a variety of forms and has been found to be a valid and reliable instrument (Dempsey \& Johnson, 1998; Klein \& Freitag, 1991; Song \& Keller, 2001; Rodgers \& Withrow-Thorton, 2005).

\section{Procedure}

The researcher was the primary instructor for both sections. Students were told that if they participated in the survey, they would receive 10 extra credit points toward the second exam. Students who did not wish to participate in the survey were not required to take the pretest and posttest or the IMMS. After the extra credit was recorded and prior to grading, the pretest, posttest, and IMMS were de-identified and coded by number and gender. By doing so, all students' rights were protected and it was not possible to determine any of the participants' identities after that point.

Lecture session. When the instructional session on lift was reached in the schedule, the researcher split the study into two instructional periods of 1 hour and 15 minutes. Students were advised to read the chapter prior to the lecture session. Students received a structured lesson in the first session on the topic. Students performed the lab related to the topic in the second session.

During the first 5 minutes of the lecture session, the instructor administered the pretest. The researcher anticipated that the students would be equivalent in pretest knowledge based on the fact that they had the basic minimum prerequisites in math and physics. Students were given a multiple choice test and were instructed to complete a Scantron-like sheet with their answers. 
Lab session. The lab session was broken into four parts. The lab session received 5 minutes of instruction on the completion of the lab. The treatment group received an additional 5 minutes of instruction on the use of FoilSim. The control group and the treatment groups were given 50 minutes to complete the lab. At the end of the lab, students were given 10 minutes to take the posttest. After the quiz, the IMMS was administered and students had 10 minutes to complete it. The IMMS was administered in accordance with the instructions given by Keller (2006).

Instructor bias. The researcher served as the instructor during the lecture and lab sessions during the study. To reduce possible error due to instructor bias, the lecture lesson plan was followed by the instructor during both sessions. The lecture notes presented on PowerPoint slides was also used during both sessions in conjunction with the lecture lesson plan to ensure that both groups received the same material.

\section{Results}

\section{Demographic and Descriptive Data}

There were 52 student participants in this study from two sections of AS 309 Aerodynamics. Both sections were offered in the spring 2009 semester at ERAU in Daytona Beach, Florida. Student samples were representative of the typical demographic distribution in an aeronautical science course (Table 1).

Table 1

Demographic Data

\begin{tabular}{lcc}
\hline \multicolumn{1}{c}{ Gender } & Control Group & Treatment Group \\
\hline Male & 21 & 19 \\
Female & 8 & 4 \\
\hline
\end{tabular}




\section{Score Results}

Student performance in the pretest indicated that the students did not have a strong grasp of basic aerodynamic concepts. Students in the treatment group scored higher on the pretest than the control group (Table 2). The scores were based on a maximum of 100 points. An ANOVA indicated that there was no significant difference in the pretest scores of the two groups.

Table 2

Pretest Posttest Descriptive Data

\begin{tabular}{lrr}
\hline \multicolumn{1}{c}{ Data Type } & Control Group & Treatment Group \\
\hline Pretest & & \\
$\mathrm{n}$ & 29 & 23 \\
mean & 34.48 & 36.52 \\
standard deviation & 21.31 & 21.44 \\
high & 80 & 80 \\
low & 0 & 0 \\
& & \\
Posttest & 29 & 23 \\
$\mathrm{n}$ & 63.44 & 64.78 \\
mean & 14.95 & 19.51 \\
standard deviation & 90 & 100 \\
high & 30 & 20 \\
$\quad$ low & & \\
& &
\end{tabular}

Performance. Students in the treatment group scored higher on the posttest (Table 2). Data consisted of mean scores and results from analysis of covariance (ANCOVA). The scores were based on a maximum of 100 points.

Posttest grades were lower than expected. An ANCOVA was used to test whether there was any significant difference in the mean scores. Data used in the ANCOVA were posttest scores as the dependent variable and pretest scores as the covariate. The data were found to be normally distributed and linear. Basic assumptions for the use of ANCOVA were met.

Motivation. Students in the treatment group did not have a higher level of motivation as measured by the IMMS (Table 3). Data consisted of mean scores and results from analysis of 
covariance (ANCOVA). The scores were based on a maximum of 170 points. The highest possible score would indicate a high level of overall motivation. An ANCOVA was used to test whether there was any significant difference in the mean scores. IMMS scores represented the dependent variable used in the ANCOVA. The data was found to be normally distributed and linear and met the basic assumptions for the use of ANCOVA.

Table 3

IMMS Descriptive Data

\begin{tabular}{lrc}
\hline Data Type & Control Group & Treatment Group \\
\hline $\mathrm{n}$ & 29 & 23 \\
Mean & 116.79 & 106.70 \\
Standard Deviation & 22.43 & 24.42 \\
High & 162 & 155 \\
Low & 60 & 59 \\
\hline
\end{tabular}

\section{Data Analysis}

Research Question 1. How does the instructional strategy of simulation influence performance of students in an aeronautical science aerodynamics class? The null hypothesis was that students who use the computer-based simulation will not have a higher level of performance on a posttest than control group students.

The mean scores of overall student performance on the posttest was 63.572 for the control group and 64.627 for the treatment group. An ANCOVA was performed on the posttest data using pretest as the covariate. The $f$ statistic, $f(1,49)=0.049$ (Table 1), showed that there was a statistical difference in the means of the two groups; therefore, the null was rejected. Using the instructional strategy of simulation produced a higher level of posttest performance. 
Table 4

ANCOVA Results From the Posttest

\begin{tabular}{|c|c|c|c|c|c|c|}
\hline Source & $\begin{array}{l}\text { Type III } \\
\text { Sum of } \\
\text { Squares }\end{array}$ & $\mathrm{df}$ & $\begin{array}{l}\text { Mean } \\
\text { Square }\end{array}$ & $\mathrm{F}$ & Sig. & $\begin{array}{c}\text { Partial } \\
\text { Eta } \\
\text { Squared }\end{array}$ \\
\hline $\begin{array}{l}\text { Corrected } \\
\text { Model }\end{array}$ & $452.981^{\mathrm{a}}$ & 2 & 226.491 & .782 & .463 & .031 \\
\hline Intercept & 46999.230 & 1 & 46999.230 & 162.193 & $.000^{*}$ & .768 \\
\hline Pretest & 430.144 & 1 & 430.144 & 1.484 & .229 & .029 \\
\hline Group & 14.230 & 1 & 14.230 & .049 & .826 & .001 \\
\hline Error & 14198.942 & 49 & 289.774 & & & \\
\hline Total & 227900.000 & 52 & & & & \\
\hline $\begin{array}{l}\text { Corrected } \\
\text { Total }\end{array}$ & 14651.923 & 51 & & & & \\
\hline
\end{tabular}

a. $\mathrm{R}$ Squared $=.031$ (Adjusted R Squared $=-.009$ )

$* \mathrm{p}<0.05$

Research Question 2. How does the instructional strategy of simulation influence motivation in an aeronautical science aerodynamics class? The null hypothesis was that students who use the computer-based simulation will not have a higher level of motivation as measured by post treatment instruments.

The mean score of overall student performance on the IMMS was 116.788 for the control group and 106.702 for the treatment group. An ANCOVA was performed on the IMMS data. The null was accepted based on the fact that the control group scored higher than the treatment group on the IMMS. The $f$ statistic, $f(1,50)=2.478$ (Table 2 ), did not indicate a significant difference in the means of the two groups. Using the instructional strategy of simulation as an intervention did not produce students with a higher level of motivation.

Research Question 3. What are the relationships between performance and motivation? The null hypothesis was that there would not be relationships between performance and motivation. 
The Pearson's product-moment coefficient of correlation was calculated using $\mathrm{N}=52$. The Pearson's product-moment coefficient was $r=0.20$ which is considered to be negligible; therefore; the null was accepted. There is no relationship between performance and motivation.

\section{Conclusions}

A significant difference in student performance between the control group and the treatment group was found. However, results did not indicate a significant difference in motivation between the two groups and there was no relationship between performance and motivation.

\section{Discussion}

Simulation offered an alternative way to complete a required laboratory assignment. It allowed students to immediately apply (Smith \& Ragan, 1999) something they had learned in class to something that was interactive, real-time, and presented a visual representation of the interaction of variables from a model over time (Army Modeling and Simulation Office, 2003) in new and unfamiliar ways (Streif \& Naples, 2003) based on concepts presented in a classroom setting. The use of simulation allowed students to explore concepts and their relationships to their independent variables, and visually represent schema, that may not have existed in their minds (Gagné, Briggs, \& Wager, 1992).

Research Question 1. The data for Research Question 1, showed statistical evidence that the use of simulation as an instructional strategy in a highly theoretical course, can influence performance. This supports the work of Campbell et al. (2002) and their premise that technology does not facilitate learning, but the learning strategies that enable it. The learning strategy was that students would have an alternate method of exploring the lab and, therefore, intervening by representing the information, where schema may be nonexistent. 
Research Question 2. The data for Research Question 2 did not indicate a significantly higher level of motivation between the two groups. The mean score for the control group was actually higher than the treatment group, but was not found to be significantly different. Students who used simulation as an instructional strategy did not have a higher level of motivation to learn. This result was different from Rodgers and Withrow-Thorton (2005), who found that computer-based learning strategies had a significant difference on increased motivation.

Rodgers and Withrow-Thorton (2005) conducted a study on the effect that different media has on students' motivation to learn. The researchers delivered course materials to students via the use of computer-based instruction (CBI), lecture and video. The Instructional Materials Motivation Survey (IMMS) was used to evaluate overall motivation of students. CBI was found to have a significant difference on increased motivation over both lecture and video.

Research Question 3. The data for Research Question 3 did not indicate any relationships between performance and motivation. The correlation was considered to be insignificant. This data supports Keller's (1983) statement that performance is only indirectly related to motivation. It also supports Pintrich and de Groot's (1990) findings that motivation did not have a direct relation to student performance using correlation data. Pintrich (2000) suggested that the relationship that may exist would be a result of avoidance and achievement. There was no penalty in that this posttest quiz did not count. Therefore, avoidance and achievement would not have been present during this study by definition.

The lack of difference in motivation may have been the result of one area of the ARCS model being highly deficient relative to the others. If the four factors of the ARCS model had been analyzed separately, one or more may have indicated difference in motivation. 
A second possible factor was that the simulation was used in the lab in a very methodical and rigid way. Students did not have a sufficient amount of time to independently explore the simulation. This lack of exploration is a factor that would impact Keller's factors of the ARCS model.

No relationships between performance and motivation were found. Analyzing the four factors of the ARCS model may have produced a different result in correlation. It is possible that relationships exist, but were not detectable in this study.

\section{Implications of the Study}

The literature review, data analysis, and interpretation of the results have been discussed and several implications are clear. The first implication is that the use of simulation as an instructional strategy by instructors may have positive benefits. The second implication is that simulation has potential benefits if used as a study tool by students. The third implication is for university administrators as it relates to cost.

Implications for instructors. The use of simulation in a highly theoretical course allows for the replacement of expensive and/or unavailable lab equipment. The ability to graphically represent material that may not exist in the student's schema and the ability to obtain instantaneous feedback to students make simulation an optional replacement for paper-based labs. Another benefit to the use of simulation is that it is often portable to a computer lab or a student's personal computer. Instructors can use the simulation to assign additional homework assignments which allows students to work at their own pace.

Implications for students. The use of simulation by students in a highly theoretical course allows for the use of simulation in and out of the classroom. The ability to develop mental models and schema based on graphical output and instantaneous feedback gives the 
student an opportunity to bridge a gap in their knowledge during an instructional session. The portability of software to lab and home allows students the opportunity to experiment freely and may further develop their mental models and schema based on "what if" experimentation.

Implications for administrators/universities. The startup cost of many technology programs is in the cost of new laboratory equipment. Also, existing programs may need to add or replace older equipment. Simulation is less expensive. By replacing laboratory equipment with simulation, labs can also be performed via distance learning and perform at the same or a higher level. The point of improved performance also addresses retention. Higher retention means a higher overall revenue for a university.

\section{Limitations of the Study}

There were four primary limitations to this study. The first limitation was that this research was conducted over one lesson and one lab. This deprives the researcher from obtaining additional data points downstream of the lesson. The research was designed in this way to isolate the variable to a specific learning objective in an attempt to reduce error.

The second limitation was that the motivational tool did not measure the motivation of students prior to the application of the treatment. In hindsight, the researcher could have utilized another instrument separate from the IMMS to measure pretreatment motivation.

The third limitation was that the study was performed over two sections and a total of 52 students. The lack of sections was due to time constraints. The inclusion of numerous sections would require several semesters to complete the study.

The fourth limitation of the study was that random assignment to groups was not possible. This limitation was due to these courses occurring in a university setting. Students select which section they will attend. 


\section{Summary}

The main purpose of this study was to examine the use of simulation as an instructional strategy in a highly theoretical aeronautical science aerodynamics course. The results of this study demonstrate that the use of simulation as an instructional strategy can improve student performance in specific instructional objectives. Implications are that simulations may be used by instructors to bridge gaps in mental models and schema present in students.

Recommendations included the replication of this study in other disciplines, performing the study over multiple lessons, researching age and gender, and researching the use of simulation as a tool for homework. Limitations were discussed such as the limited scope of one lesson, a lack of prelesson motivational measurement, and limited sample size. Further research is needed to determine the methods and scope in which to deploy simulation in highly theoretical courses and the educational environment. 


\section{References}

Army Modeling and Simulation Office. (2003). Simulation operations handbook. U.S. Army: Author.

Benson, T. J. (1996). Interactive educational tool for classical airfoil theory. Unpublished manuscript.

Campbell, J. O., Bourne, J. R., Mosterman, P. J., \& Brodersen, A. J. (2002). The effectiveness of learning simulations for electronics laboratories. Journal of Engineering Education, 91(1), 81-87. http://dx.doi.org/10.1002/j.2168-9830.2002.tb00675.x

Davidovitch, L., Parush, A., \& Shtub, A. (2006). Simulation-based learning in engineering education: Performance and transfer in learning project management. Journal of Engineering Education, 95(4), 289-299. http://dx.doi.org/10.1002/j.21689830.2006.tb00904.x

Dempsey, J. V., \& Johnson, R. B. (1998). The development of the ARCS gaming scale. Journal of Instructional Psychology, 25(4), 215-221.

Gagné, R. (1977). The Conditions of learning (3rd ed.) New York, N.Y.: Holt, Rinehart, and Winston.

Gagné, R. M., Briggs, L. J., \& Wager, W. W. (1992). Principles of instructional design (4 ${ }^{\text {th }}$ ed.). Orlando, FL: Holt, Rinehart, and Winston, Inc.

Keller, J. (1983). Motivational Design of Instruction. In C. M. Reigeluth (Ed.), Instructional design theory and models: An overview of their current status (p. 383-434). Hillsdale: NJ: Lawrence Erlbaum Associates, Publishers.

Keller, J. (1987). Development and use of the ARCS model of instructional design. Journal of Instructional Development, 10(3), 2-11. http://dx.doi.org/10.1007/BF02905780 
Keller, J. (1993). Manual for Instructional Materials Motivational Survey (IMMS). Unpublished Manuscript, Florida State University, Tallahassee.

Keller, J. (2006). Development of Two Measures of Student Motivation. Unpublished Manuscript, Florida State University, Tallahassee.

Klein, J. D., \& Freitag, E. (1991). Enhancing motivation using an instructional game. Journal of Instructional Psychology, 181(2), 111-116.

Laurillard, D. (2002). Rethinking university teaching ( $2^{\text {nd }}$ ed.). New York, NY: RoutledgeFalmer.

Pintrich, P. R, \& de Groot, E. V. (1990). Motivational and self-regulated learning components of classroom academic performance. Journal of Educational Psychology, 82(1), 33-40. http://dx.doi.org/10.1037/0022-0663.82.1.33

Pintrich, P. R. (2000). An achievement goal theory perspective on issues in motivation terminology, theory, and research. Contemporary Educational Psychology 25, 92-104. http://dx.doi.org/10.1006/ceps.1999.1017

Proctor, M. D., \& Gubler, J. C. (2001). Creating the potential for organizational learning through interactive simulation debriefing sessions. Performance Improvement Quarterly, 14(3), 8-19. http://dx.doi.org/10.1111/j.1937-8327.2001.tb00216.x

Rodgers, D. L., \& Withrow-Thorton, B. J. (2005). The effect of instructional media on learner motivation. International Journal of Instructional Media, 21(4), 333-342.

Schmidt, S. J. (2003). Active and cooperative learning using web-based simulations. Journal of Economic Education, 34(2), 151-167. http://dx.doi.org/10.1080/00220480309595209

Smith, P. L., \& Ragan, T. J. (1999). Instructional Design ( $2^{\text {nd }}$ ed.). Hoboken, NJ: John Wiley \& Sons. 
Song, S. H., \& Keller, J. M. (2001). Effectiveness of motivationally adaptive computer-assisted instruction on the dynamic aspects of motivation. Education Technology Research and Development, 49(2), 5-22. http://dx.doi.org/10.1007/BF02504925

Streif, P. S., \& Naples, L. M. (2003). Design and evaluation of problem solving courseware modules for mechanics of materials. Journal of Engineering Education, 92(3), 239-247. http://dx.doi.org/10.1002/j.2168-9830.2003.tb00764.x

Wekesa, E., Kiboss, J., \& Ndirangu, M. (2006). Improving students' understanding and perception of cell theory in school biology using a computer-based instruction simulation program. Journal of Educational Multimedia and Hypermedia, 15(4), 397-410. 